\title{
Ubiquinone, plastoquinone and related substances
}

\author{
By M. McC. BARnes and R. A. MorTon, Biochemistry Department, University of \\ Liverpool
}

The classical work of Dam, Almquist and Doisy and their colleagues on vitamins $\mathrm{K}$ in relation to structure, nutrition, and in particular to prothrombin, has long been accepted. Indeed, for some time there has been a relative dearth of papers on the $K$ vitamins. In recent years, however, there has been considerable renewed interest in quinones which are found to occur widely distributed in living tissues. Chronologically, this revival of interest began when Kofler (I946) found a new quinone in dried lucerne. Comparison of its absorption spectrum with those of a range of substituted quinones suggested that the compound isolated was a tri-substituted p-benzoquinone, and physical studies suggested a large molecular weight, of the order of 800 . The full importance of this discovery was not realized at the time. The original source of what is often referred to as Kofler's quinone was lucerne (alfalfa), but the same compound was later isolated from oat plants, nettles, ivy leaves, pine needles and horse-chestnut leaves.

\section{Ubiquinone}

A short time later, Festenstein and his colleagues (Festenstein, I950; Lowe, Morton \& Harrison, 1953; Festenstein, Heaton, Lowe \& Morton, r 955), working in Liverpool, found a new substance, referred to at that time as substance A (SA), in the unsaponifiable lipid of horse intestinal mucosa. SA was subsequently shown to be present in yeast, and in fact to be very widely distributed. As it was of quinone nature the name ubiquinone was suggested (Morton, Wilson, Lowe \& Leat, I957). The details of the complete characterization of ubiquinone have been reviewed recently (Morton, 1961). The full structure was shown to be 2,3-dimethoxy-5-methyl$p$-benzoquinone with a polyisoprenoid side-chain attached to carbon 6 of the benzoquinone nucleus (Morton, Gloor, Schindler, Wilson, Chopard-dit-Jean, Hemming, Isler, Leat, Pennock, Rüegg, Schweiter \& Wiss, 1958).<smiles>CCC(C)=CCC1=C(C)C(=O)C(OC)=C(OC)C1=O</smiles>

Ubiquinone

Ubiquinone, as first isolated, had a $\mathrm{C}_{50}$ side-chain, with ten unconjugated double bonds, i.e. it contained ten isoprene units. But several other homologues were later found in other materials with from six to nine isoprene units, $\mathrm{C}_{30}-\mathrm{C}_{45}$ side-chains. The homologues are distinguished by giving the number of carbon atoms in the 
side-chain as follows, e.g. ubiquinone (50) that originally discovered, and ubiquinone (30) that found in yeast (Gloor, Isler, Morton, Rüegg \& Wiss, 1958).

Concurrently and independently Crane and Lester, working at the Enzyme Institute in Wisconsin and interested in electron transport mechanisms, were investigating mitochondrial lipids. They isolated from ox-heart mitochondria a substance of quinone nature which had a maximum in its absorption spectrum at $275 \mathrm{~m} \mu$ (in ethanol), and they named this compound $\mathrm{Q}_{275}$ (Crane, Hatefi, Lester \& Widmer, 1957). It was later shown that $\mathrm{Q}_{275}$ was capable of reversible reduction, and a requirement for it in the succinoxidase system was strongly suspected, so they proposed the new name coenzyme $\mathrm{Q}$.

Correspondence between the Liverpool group and the Wisconsin group showed that ubiquinone and coenzyme Q were identical. Lester, Crane \& Hatefi (1958) isolated a number of coenzymes $Q$ from various other tissues and micro-organisms. These coenzymes were found to differ slightly in physical properties. The differences were shown to be due to varying numbers of isoprene units in the side-chain, from six to ten isoprene units were found, and the compounds were designated coenzyme $\mathrm{Q}_{6}$ to coenzyme $\mathrm{Q}_{10}$ according to the number of isoprene groups in the side-chain. The distribution of coenzymes $Q$ (ubiquinones) has been summarized by Lester \& Crane (1959) and by Ramasarma (1961).

The independent discovery of ubiquinone and coenzyme $Q$ led to the adoption of two trivial names. Coenzyme $Q$ is used predominantly in North America, and ubiquinone is more generally used in Europe. The Commission on Enzymes of the International Union of Biochemistry (196I) in their interim report recommends that the trivial name ubiquinone should be generally adopted and the use of coenzyme $Q$ discontinued. UQ is suggested as an abbreviation, and a numerical suffix may be added to indicate the number of isoprene units, e.g. ubiquinone (50) would become $\mathrm{UQ}_{10}$.

\section{Ubichromenol}

In the course of the Liverpool investigation another compound (substance $\mathrm{C}$ or $\mathrm{SC}$ ) was found. Lowe et al. (1953) isolated SC from the unsaponifiable lipid in the liver of vitamin A-deficient rats. Cunningham $\&$ Morton (1959) found SC in traces in the livers of several species. Lowe, Morton \& Vernon (1957) found SC in the

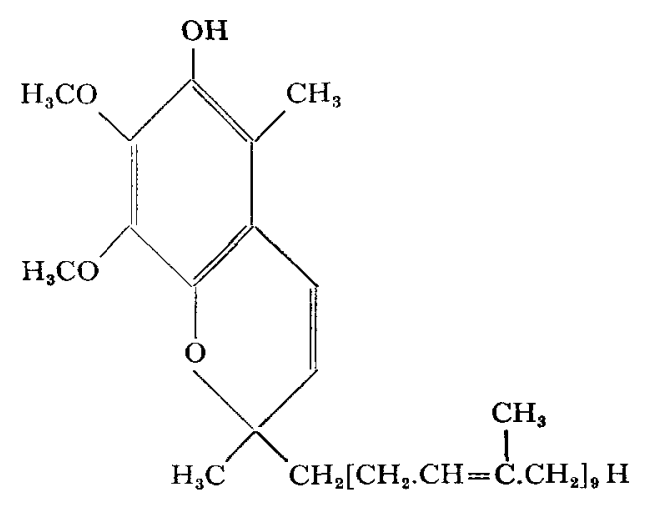

Ubichromenol 
kidneys of several species and in fowl liver and intestine. Mervyn \& Morton (1959) found SC in 'normal' human kidney. The details of the characterization have recently been reported elsewhere (Morton, I96r). SC was shown to be an isomer of ubiquinone, in which the first three carbon atoms of the side-chain with one of the quinone oxygens have cyclized to form a chromene ring.

The trivial name ubichromenol was suggested. The nomenclature of the ubichromenols is derived from that of the ubiquinones. The compound which is the isomer of ubiquinone (50) is referred to as ubichromenol (50), although it has only forty-six carbon atoms in the side-chain.

\section{Plastoquinone}

Crane \& Lester (1958) also found another new substance, but this was also a quinone $\left(\mathrm{Q}_{254}\right)$. It was found in photosynthetic micro-organisms and plants, associated principally with the chloroplasts (Crane, 1959), and was given the name plastoquinone. It was in fact found to be the same quinone as that originally isolated by Kofler (1946). It is 2,3-dimethyl-p-benzoquinone with a polyisoprenoid side-chain attached to carbon 5 of the benzoquinone nucleus. The side-chain contains fortyfive carbon atoms (nine isoprene units), and is similar in structure to an alcohol, solanesol, isolated by Rowland, Latimer \& Giles (1956) from tobacco leaves (Trenner, Arison, Erickson, Shunk, Wolf \& Folkers, I959; Kofler, Langemann, Rüegg, Gloor, Schweiter, Wursch, Wiss \& Isler, 1959).

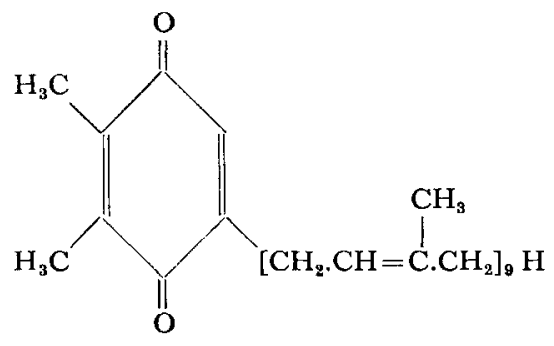

Plastoquinone

Solanesol has since been found in animal tissues (Gloor \& Wiss, 1960), but it is thought to be derived from the food, rather than synthesized by the animal.

Ubiquinone is found almost universally in tissues. It occurs in muscle, heart, liver, kidney, pancreas, spleen and other organs, associated principally with the mitochondria. It is a quinone capable of reversible reduction and it appears to be involved in the electron transport system (see Redfearn, 1961). The precise function of ubiquinone in the electron transport system is still under discussion and there is no evidence that ubichromenol is involved.

Plastoquinone is found in plants associated principally with the chloroplasts. It also is a quinone capable of reversible reduction, and appears to fulfil a role in photosynthesis analogous to that of ubiquinone in oxidative phosphorylation (see Bishop, I96r). 


\section{Solanachromene}

Rowland (1958) isolated a phenolic compound from cured tobacco leaves and gave it the name solanachromene, showing it to be a substituted 2,7,8-trimethyl-6hydroxy-chromene. In fact solanachromene is the cyclized isomer of plastoquinone, just as ubichromenol is the cyclized isomer of ubiquinone.

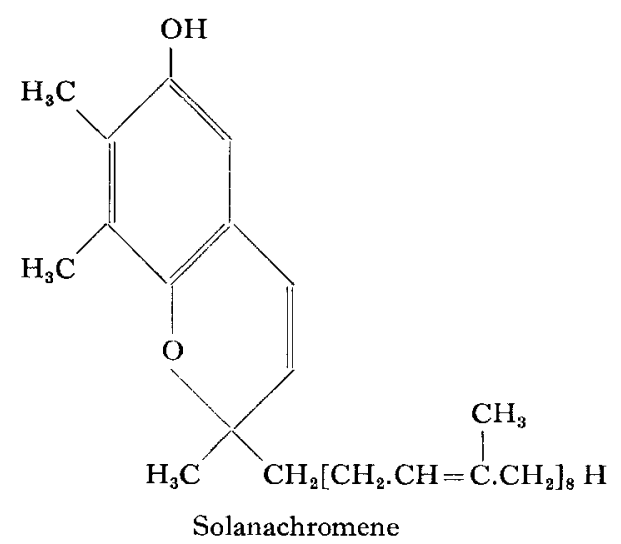

Solanachromene has not been isolated from any source other than cured tobacco leaves, as yet. It is not clear whether the cyclization is a natural phenomenon, or an artifact of the commercial processing of tobacco leaves.

\section{Vitamins $K$}

The compounds described above can all be regarded as derivatives of $p$-benzoquinone. In addition, substituted naphthaquinones are widely distributed in living tissues; these are the vitamins $\mathrm{K}$. The original vitamin $\mathrm{K}$ (vitamin $\mathrm{K}_{1}$ or phylloquinone) was isolated from a plant source. It has the systematic name 2-methyl-3phytyl-I,4-naphthaquinone. The side-chain attached to carbon 3 is similar in structure to the plant alcohol phytol $\left(\mathrm{C}_{20} \mathrm{H}_{39} \mathrm{OH}\right)$.

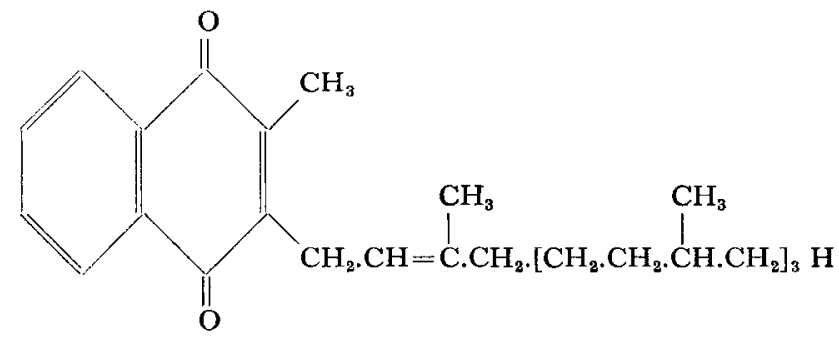

Vitamin $\mathbf{K}_{1}$

Subsequently other vitamins $\mathrm{K}$ have been found. Vitamin $\mathrm{K}_{2}$, originally found in micro-organisms by Doisy, has a polyisoprenoid side-chain in place of the phytyl 
residue of vitamin $\mathrm{K}_{1}$. Isler, Rüegg, Chopard-dit-Jean, Winterstein \& Wiss (1958), repeating the work, showed that the side-chain of the predominating vitamin $\mathrm{K}_{2}$ contained seven isoprene units $\left(\mathrm{C}_{35} \mathrm{H}_{57}\right)$. Francis, Madinaveitia, Macturk \& Snow (1949), Noll (1958) and Noll, Rüegg, Gloor, Ryser \& Isler (1960) reported another homologue with nine isoprene units in the side-chain $\left(\mathrm{C}_{45} \mathrm{H}_{73}\right)$. This conclusion was proved by synthesis from menaphthone (2-methyl-I,4-naphthaquinone) and solanesol $\left(\mathrm{C}_{45} \mathrm{H}_{23} \mathrm{OH}\right)$. The vitamins $\mathrm{K}_{2}$ can be regarded as a series of homologues with polyisoprenoid side-chains, differing only in the number of isoprene units in the side-chain attached to the naphthaquinone nucleus, just as the ubiquinones are a series of homologues with different numbers of isoprene units in the side-chain attached to a $p$-benzoquinone nucleus. In addition there are phylloquinone (vitamin $\mathrm{K}_{1}$ ), which is found in plants, and has a branched, but nearly fully saturated sidechain and the simple compound menaphthone (vitamin $\mathrm{K}_{3}$ ) which with other synthetic compounds also has vitamin $\mathrm{K}$ activity. The ubiquinones so far isolated all have unsaturated polyisoprenoid side-chains, including those isolated from plant sources. It appears that the benzoquinone nucleus can be synthesized in the animal body from normal food constituents, so that a dietary requirement for substituted

$p$-benzoquinones has not been demonstrated. The methyl-naphthaquinone nucleus evidently cannot be synthesized and must be supplied in the diet.

Martius (I96I) has reviewed the metabolic relationships between the different vitamins $K$. He and his coworkers, have shown that menaphthone (vitamin $K_{3}$ ), is converted into a polyisoprenoid derivative vitamin $\mathrm{K}_{2}(20)$ in the animal body. Similarly vitamin $\mathrm{K}_{1}$ was shown to lose its phytyl side-chain and to be converted also into vitamin $\mathrm{K}_{2}(20)$. Martius, therefore, suggested that the functional form of vitamin $\mathrm{K}$ in the animal is a vitamin $\mathrm{K}_{2}$ with a $-\mathrm{C}_{20} \mathrm{H}_{33}$ side-chain.

Brodie and coworkers have found a naphthachroman in preparations of $\mathrm{Myco}$ bacterium phlei. They suggest that there is a direct relationship between the formation of the chroman and oxidative phosphorylation, and that vitamin $\mathrm{K}$ acts in oxidative phosphorylation via the chroman (Brodie, I96I).

Napthachroman is also referred to as naphthatocopherol, because the ring formation is chroman, as in the tocopherols, and not chromene as in ubichromenol and solanachromene.

\section{Vitamin $E$}

Until recently it was generally held that all the naturally occurring vitamins $E$ were methylated derivatives of the parent compound tocol. Green, McHale, Marcinkiewicz, Mamalis \& Watt (I959) and Green, Mamalis, Marcinkiewicz \& McHale (I960) isolated from wheat bran a tocopherol which corresponded to $\beta$-tocopherol with an unsaturated side-chain; they called it $\epsilon$-tocopherol, and later isolated $\zeta_{1}$-tocopherol which corresponded to an unsaturated $\alpha$-tocopherol. All the tocopherols can be regarded as cyclized-p-benzoquinones with the formation of a chroman ring. These 'newer' tocopherols have polyisoprenoid side-chains, as do the ubiquinones, plastoquinone and vitamins $\mathrm{K}_{2}$. The 'original' tocopherols have a side-chain corresponding to phytol, as does vitamin $\mathrm{K}_{1}$. 

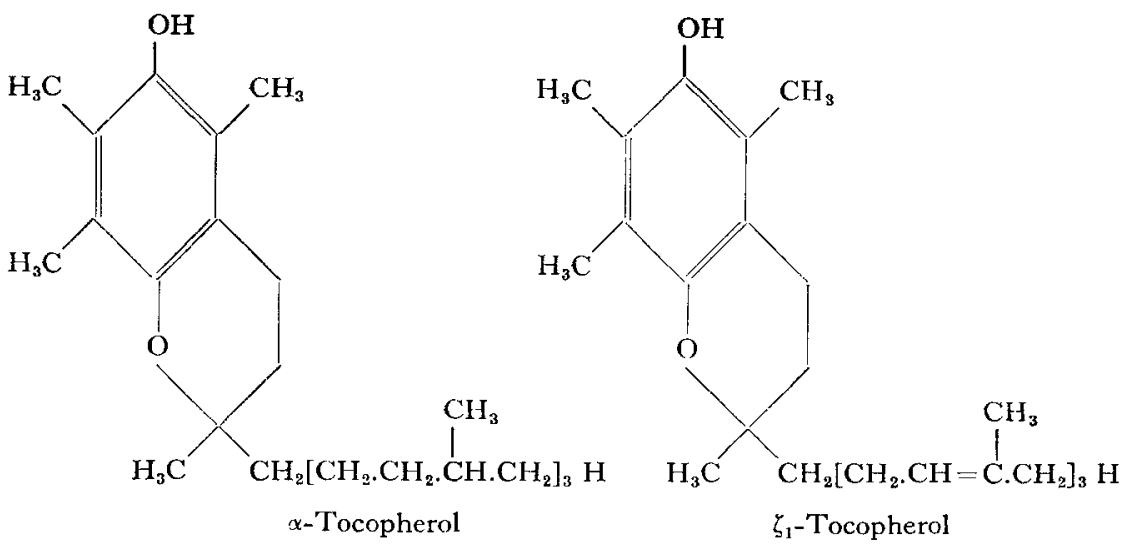

Dolichol

Pennock, Hemming \& Morton (I960) reported the presence of an alcohol with a very long chain in the unsaponifiable lipid of human kidney. Comparison with alcohols of known composition and their derivatives suggested that the alcohol contained 95-100 carbon atoms and apparently a single primary alcohol group, and the iodine uptake suggested nineteen to twenty unconjugated double bonds. O. Isler, U. Gloor \& J. Wursch (1960, private communication) found a molecular weight of $\mathbf{1 4 2 2}$ for the acetate derivative by isotope dilution. The empirical formula is thus $\mathrm{C}_{100} \mathrm{H}_{161} \mathrm{OH}$, and a suitable name seemed to be dolichol. Dolichol has been found also in ox intestine, ox kidney, pig kidney, pig heart, pig liver, rat liver, human liver, human stomach, sheep brain, and in the spadix of Arum maculatum. The biological role of this comparatively large molecule is not known. Dolichol appears to be a polyisoprenoid substance, and it may in some way be related to the substances under review.

\section{Discussion}

The chemical composition of a number of minor unsaponifiable lipid components of natural tissues has been described. All were independently discovered and investigated on their own merits. Various lines of research have, however, converged. Little is known about the precise biochemical function of any of these substances. Some of the disorders that result from their absence have been described in detail but the metabolic dysfunctions cannot be described in precise chemical terms. It seems very unlikely that a group of substances presenting so many chemical similarities can be devoid of biochemical interrelationships.

Johnson, Crider, Shunk, Linn, Wong \& Folkers (1961) found that ubichromenol had vitamin $\mathrm{E}$ activity, as measured by the gestation-resorption test in the rat. However, the related compound with a chroman ring, ubichromanol, had no vitamin $\mathrm{E}$ activity, so the possibility that ubichromenol was acting as a non-specific antioxidant substituting for vitamin $\mathrm{E}$ cannot be excluded.

The levels of ubiquinone and ubichromenol in the tissues can be affected by the nutritional state of the animal. Deficiency in vitamin A leads to a considerable 
increase in the ubiquinone and ubichromenol levels in the liver of rats (Heaton, Lowe \& Morton, 1957; Morton \& Phillips, 1959a). This cannot be a simple, direct relationship because vitamin A deficiency in the domestic fowl leads to no appreciable change in liver content of ubiquinone or ubichromenol (Lowe, Morton, Cunningham \& Vernon, I957). Thiamine and riboflavin deficiencies were found to have no effect on ubiquinone or ubichromenol levels in the rat, but pantothenic acid deficiency led to an increase in the ubiquinone level in rat liver (Diplock, Bunyan, Green \& Edwin, 1961). However, Aiyar, Sulebele, Rege \& Sreenivasan (1959) reported a slight decrease in rat liver ubiquinone in pantothenic acid deficiency. Morton \& Phillips ( $1959 b$ ) found that vitamin $\mathrm{K}$ deficiency had no effect on the level of ubiquinone or ubichromenol in the rat. Some of the relationships between the tocopherols and ubiquinone and ubichromenol have been studied by Diplock, Edwin, Bunyan \& Green (I96I) and Edwin, Diplock, Bunyan \& Green (I96I) who found that the administration of vitamin $\mathrm{E}$ markedly increased concentrations of ubiquinone in the tissues of the rat. How selenium can act in a way resembling the vitamins $\mathrm{E}$ is a major problem, but the above authors found selenium produced changes in ubiquinone levels similar to those produced by $\alpha$-tocopherol, with the notable exception that selenium had no effect on the level of ubiquinone in rat uterus. Harris, Ludwig \& Schwarz (1958) have reported that selenium is ineffective in the rat gestationresorption test.

\section{Possible functions of quinones}

Ramasarma (I96I) rightly points out that it is the initial reaction, the esterification of inorganic phosphate, which is the real crux of the problem of the mechanism of oxidative phosphorylation. Several hypothetical schemes for this primary reaction have been proposed. Ramasarma (196I) and Brodie (I96I) have published reviews of a number of these schemes. In general the hypothesis is that the initial product is a quinol phosphate, which is activated by the removal of two electrons, and the energy-rich enol phosphate transferred to ADP.
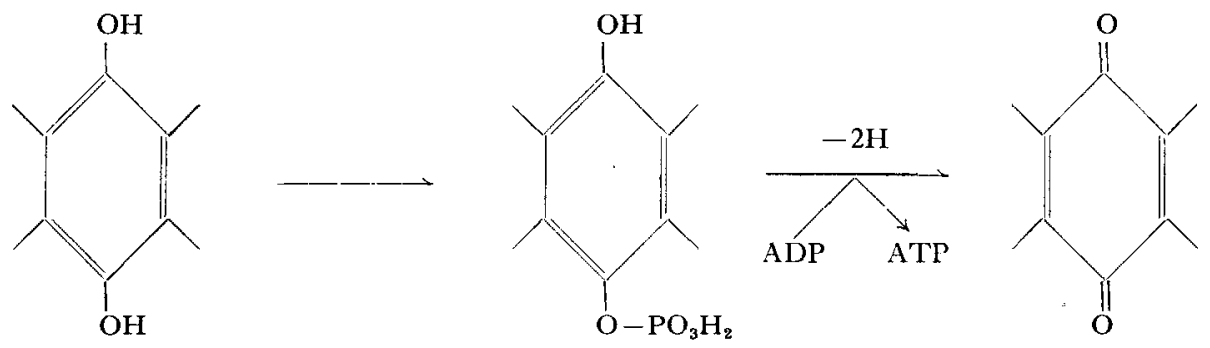

The evidence for such a series of reactions is perhaps strongest for vitamin $\mathrm{K}$ in Mycobacterium phlei systems. Russell \& Brodie (I960) found that a phosphate derivative of vitamin $K$, which could transfer its phosphate to ADP, was formed during anaerobic incubation of $M$. phlei extracts with vitamin $\mathrm{K}$. No such direct experimental evidence has been obtained with ubiquinone systems. Schemes which involve the formation of ubichromenol phosphate have been postulated, but there is, as yet, no direct evidence that ubichromenol is involved in oxidative phosphorylation. 
Nor has solanachromene been shown to be involved in photosynthetic phosphorylation, and it is possible that both ubichromenol and solanachromene are products of side-reactions :
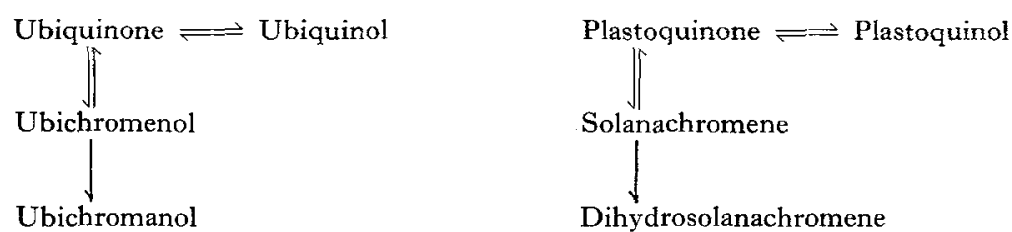

Solanachromene, in fact, has been isolated from cured tobacco leaves only and pending further evidence may well be regarded as an artifact of the commercial processes. Ubichromenol is more widely distributed and is almost certainly a natural product (Hemming, Laidman, Morton \& Pennock, I96r), though its natural occurrence does not necessarily imply a biochemical function. The chroman derivatives, ubichromanol and dihydrosolanachromene, have not been found in natural tissues. Dihydrosolanachromene would be very like the 'newer' tocopherols of Green and coworkers,

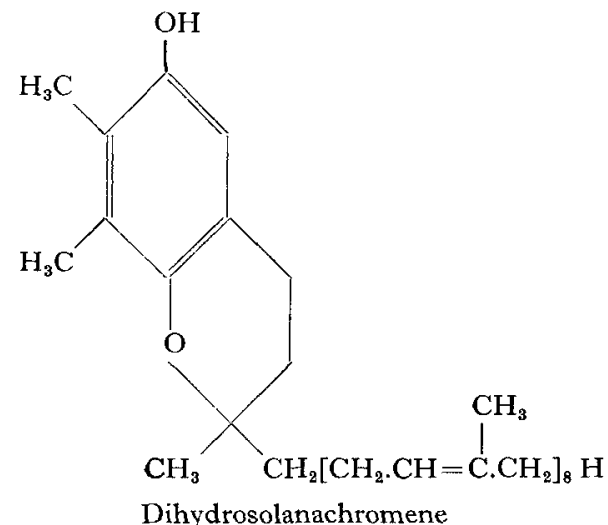

but with a larger polyisoprenoid side-chain. It would be interesting to determine whether dihydrosolanachromene has vitamin $\mathrm{E}$ activity. Ubichromanol also has a larger side-chain, but in addition, differs from the tocopherols in having methoxy groups attached to the benzoquinone nucleus. Johnson et al. (r96r) found that ubichromanol had no vitamin $\mathrm{E}$ activity in the rat gestation-resorption test.

Brodie (196I) suggests that chroman formation, from vitamin K, is a necessary stage in the production of ATP by $M$. phlei extracts.

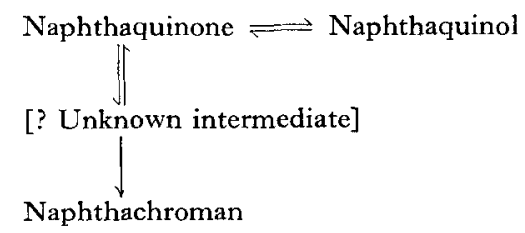

It appears, therefore, that the mode of action of vitamin $\mathrm{K}$ in oxidative phosphorylation is different from the modes of action of ubiquinone and plastoquinone. The 
chroman derivatives of these latter compounds are not known to occur naturally and the evidence does not suggest that the chromene derivatives are involved, more especially with plastoquinone because of the very limited distribution of solanachromene. It seems surprising that the process of phosphorylation involving vitamin $\mathrm{K}$ should differ much from that involving ubiquinone, and further results may indicate similar pathways.

The relationship, if any, of the tocopherols to these systems is obscure, especially since no function other than antioxidant activity has been clearly demonstrated. Several workers have suggested a function in oxidative phosphorylation but the evidence obtained so far is not conclusive. A quinone derivative, tocopherylquinone and a quinol have been found in traces in animal tissues, and both have been reported to have vitamin E activity in the rat gestation-resorption test (Green, Diplock, Bunyan, Edwin \& McHale, 1961). Simon, Eisengart, Sundheim \& Milhorat (r956) isolated a metabolite of $\alpha$-tocopherol from human urine. Green, Edwin, Diplock \& Bunyan (I96I) suggest that this compound, which they call tocopheronic acid, is the active form of vitamin $\mathrm{E}$, or closely allied to it.

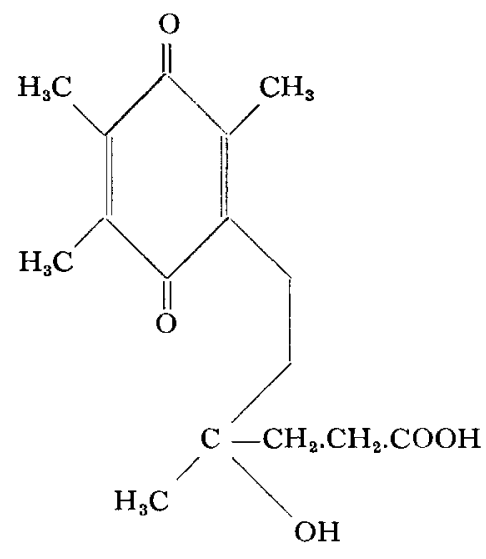

Tocopheronic acid

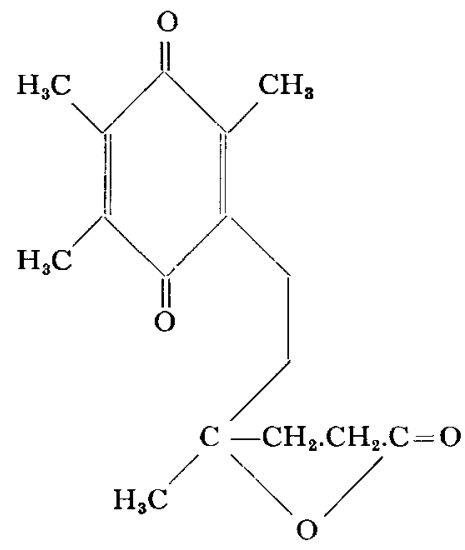

Tocopheronolactone

Green and his coworkers found that the lactone derived from tocopheronic acid, tocopheronolactone, was more active than $\alpha$-tocopherol in increasing ubiquinone concentrations in rat tissues. Tocopheronic acid prevents respiratory decline in ratliver slices deficient in vitamin $\mathrm{E}$ and selenium (Mertz \& Schwarz, 1959) and restores oxidation of $\alpha$-ketoglutarate in vitamin $\mathrm{E}$ deficient rat-liver homogenates (Corwin \& Schwarz, 1960). Bunyan, Green, Diplock \& Edwin (196r) reported the presence in rat liver of an enzyme which couples the reduction of tocopheronolactone to the oxidation of reduced pyridine nucleotides, evidence which confirms the suggestion of Schwarz (1954) that tocopherol, or an active metabolite of tocopherol, is involved in oxidation-reduction reactions.

\section{REFERENCES}

Aiyar, A. S., Sulebele, G. A., Rege, D. V. \& Sreenivasan, A. (1959). Nature, Lond., 184, 1867. Bishop, N. I. (1961). In Quinones in Electron Transport, p. 385. Ciba Found. Symp. London: J. and A. Churchill. 
Brodie, A. F. (I961). Fed. Proc. 20, 995.

Bunyan, J., Green, J., Diplock, A. T. \& Edwin, E. E. (196r). Biochem. biophys. Acta, 49, 420.

Commission on Enzymes of the International Union of Biochemistry ( $196 \mathrm{r}$ ). Report. London: Pergamon Press.

Corwin, L. M. \& Schwarz, K. (1960). Nature, Lond., 186, 1048.

Crane, F. L. (1959). Plant Physiol. 34, 128.

Crane, F. L., Hatefi, Y., Lester, R. L. \& Widmer, C. (1957). Biochim. biophys. Acta, 25, 220.

Crane, F. L. \& Lester, R. L. (1958). Plant Physiol. 33, vii

Cunningham, N. F. \& Morton, R. A. (1959). Biochem. F. 72, 92.

Diplock, A. T., Bunyan, J., Green, J. \& Edwin, E. E. (I96I). Biochem. F. 79, 105.

Diplock, A. T., Edwin, E. E., Bunyan, J. \& Green, J. (r961). Brit. F. Nutr. 15, 425.

Edwin, E. E., Diplock, A. T., Bunyan, J. \& Green, J. (1961). Biochem. Y. 79, 91.

Festenstein, G. N. ( $195^{\circ}$ ). Provitamin D and other compounds in animal lipids. Ph.D. Thesis, University of Liverpool.

Festenstein, G. N., Heaton, F. W., Lowe, J. S. \& Morton, R. A. (1955). Biochem. F. 59, 558.

Francis, J., Madinaveitia, J., Macturk, H. M. \& Snow, G. A. (1949). Nature, Lond., 163, 365.

Gloor, U., Isler, O., Morton, R. A., Rüegg, R. \& Wiss, O. (1958). Helv. chim. acta, 4r, 2357.

Gloor, U. \& Wiss, O. (1960). Biochem. biophys. Res. Conmun. 2, 222.

Green, J., Diplock, A. T., Bunyan, J., Edwin, E. E. \& McHale, D. (I96I). Nature, Lond., 190, 318.

Green, J., Edwin, E. E., Diplock, A. T. \& Bunyan, J. (196r). Biochim. biophys. Acta, 49, 417.

Green, J., McHale, D., Marcinkiewicz, S., Mamalis, P. \& Watt, P. R. (1959). F. chem. Soc. p. 3362.

Green, J., Mamalis, P., Marcinkiewicz, S. \& McHale, D. (ı960). Chem. Gீ Ind. p. 73.

Harris, P. L., Ludwig, M. I. \& Schwarz, K. (1958). Proc. Soc. exp. Biol., N.Y., 97, 686.

Heaton, F. W., Lowe, J. S. \& Morton, R. A. (1957). Biochem. F. 67, 208.

Hemming, F. W., Laidman, D. L., Morton, R. A. \& Pennock, J. F. (196r). Biochem. biophys. Res. Commun. 4, 393.

Isler, O., Rüegg, R., Chopard-dit-Jean, L. H., Winterstein, A. \& Wiss, O. (1958). Helv. chim. acta, 4r, 786.

Johnson, B. C., Crider, Q., Shunk, C. H., Linn, B. O., Wong, E. L. \& Folkers, K. (rg6r). Biochem. biophys. Res. Commun. 5, 309.

Kofler, M. (1946). Jubilee Volume Emil Christoph Barrell, p. 199. Basle, Switzerland: F. Hoffmann-La Roche \& Co.

Kofler, M., Langemann, A., Rüegg, R., Gloor, U., Schweiter, U., Wursch, J., Wiss, O. \& Isler, O. (1959). Helv. chim. acta, 42, 2252.

Lester, R. L. \& Crane, F. L. (1959). F. biol. Chem. 234, 2169.

Lester, R. L., Crane, F. L. \& Hatefi, Y. (1958). F. Amer. chem. Soc. 80, 475 I.

Lowe, J. S., Morton, R. A., Cunningham, N. F. \& Vernon, J. (1957). Biochem. 7. 67, 2 I 5.

Lowe, J. S., Morton, R. A. \& Harrison, R. G. (1953). Nature, Lond., 172, 716.

Lowe, J. S., Morton, R. A. \& Vernon, J. (1957). Biochem. F. 67, 228.

Martius, C. (1961). Amer. F. clin. Nutr. 9, no. 4, part 2, p. 97.

Mertz, W. \& Schwarz, K. (1959). Proc. Soc. exp. Biol., N.Y., 102, $56 \mathrm{r}$.

Mervyn, I. \& Morton, R. A. (I959). Biochem. F. 72, 106.

Morton, R. A. (196I). In Quinones in Electron Transport, p. 5. Ciba Found. Symp. London: J. and A. Churchill.

Morton, R. A., Gloor, U., Schindler, O., Wilson, G. M., Chopard-dit-Jean, L. H., Hemming, F. W., Isler, O., Leat, W. M. F., Pennock, J. F., Rüegg, R., Schweiter, U. \& Wiss, O. (1958). Helv. chim. acta, 4I, 2343.

Morton, R. A. \& Phillips, W. E. J. (r959a). Biochem. F. 73, 416.

Morton, R. A. \& Phillips, W. E. J. (1959b). Biochem. \%. 73, 421.

Morton, R. A., Wilson, G. M., Lowe, J. S. \& Leat, W. M. F. (1957). Chem. Eீ Ind. p. I649.

Noll, H. (1958). Y. biol. Chem. 232, 919.

Noll, H., Rüegg, R., Gloor, U., Ryser, G. \& Isler, O. (I960). Helv. chim. acta, 43, 433.

Pennock, J. F., Hemming, F. W. \& Morton, R. A. (1960). Nature, Lond., r86, 470.

Ramasarma, T. (r96r). F. sci. industr. Res. 20A, 492.

Redfearn, E. R. (1961). In Quinones in Electron Transport, p. 346. Ciba Found. Symp. London: J. \& A. Churchill.

Rowland, R. L. (1958). F. Amer. chem. Soc. 80, 6r zo.

Rowland, R. L., Latimer, P. H. \& Giles, J. A. (1956). F. Amer. chem. Soc. 78, 4680.

Russell, R. J. \& Brodie, A. F. (1960). Fed. Proc. 19, A38.

Schwarz, K. (r954). Ann. N.Y. Acad. Sci. 57, 878 .

Simon, E. J., Eisengart, A., Sundheim, L. \& Milhorat, A. T. (1956). F. biol. Chem. 221, 807.

Trenner, N. R., Arison, B. H., Erickson, R. E., Shunk, C. H., Wolf, D. E. \& Folkers, K. (1959). F. Amer. chem. Soc. 81, 2026. 